\title{
NINE-PROFILE AND NINE-SEGMENT TEMPERATURE PROGRAMMER FOR MASHING APPARATUS
}

\author{
J. T. Devaraju, ${ }^{1}$ H. J. Thontadharya, ${ }^{1}$ and K. Nagaraj $^{2}$ \\ ${ }^{1}$ Department of Electronic Science, Bangalore University, Bangalore, India \\ ${ }^{2}$ USIC, Bangalore University, Bangalore, India
}

Mashing is a process of converting the grain starch into fermentable sugar by activating the malt enzymes using a hot-water steeping process. A microcontroller-based nine-profile, nine-segment temperature programmer and four-channel temperature and rpm (rotations per minute) display system for the mashing apparatus has been designed and implemented using a PIC 16F887 microcontroller. In this apparatus, a pulse width modulation (PWM)-based programmable AC voltage controller has been designed to vary mash tub temperature at required rate, and the resistance temperature detector (RTD) PT100 has been used to measure the temperature of the mash tub and sample. The software for the microcontroller has been developed using $C$ language to set the end temperature and time of the nine segments of nine temperature profiles through the keypad and also to implement the proportional integral and derivative (PID) controller to control the temperature of the mash tub as per user settings.

Keywords mashing, proportional integral and derivative (PID), resistance temperature detector (RTD), temperature controller, wort

\section{INTRODUCTION}

Mashing is the process of combining a mix of milled grain ${ }^{[1-3]}$ (typically barley with supplementary grains such as corn, sorghum, rye, or wheat ${ }^{[4]}$ ), known as the "grain bill," and water known as the "liquor." Heating this mixture by raising the temperature ${ }^{[5]}$ linearly with pauses at certain temperatures (notably $45^{\circ} \mathrm{C}, 62^{\circ} \mathrm{C}, 73^{\circ} \mathrm{C}$, etc.) allows the enzymes in the malt to break down the starch in the grain into sugars, typically maltose, to create a malty liquid called wort. ${ }^{[6-8]}$

Mashing is the brewer's term for the hot-water steeping process during which the various temperature rests (Table 1) activate different enzymes, depending upon the type of malt being used, its modification level, and

Address correspondence to J. T. Devaraju, Department of Electronic Science, Bangalore University, Bangalore 560 056, India. E-mail: devarajujt@bub.ernet.in 
TABLE 1 Optimal Rest Temperatures for Major Mashing Enzymes

\begin{tabular}{lll}
\hline Tempeature $\left({ }^{\circ} \mathrm{C}\right)$ & \multicolumn{1}{c}{ Enzyme } & Breaks Down \\
\hline 40 & $\beta$-Glucanase & $\beta$-Glucan \\
50 & Protease & Protein \\
62 & $\beta$-Amylase & Starch \\
72 & $\alpha$-Amylase & Starch \\
\hline
\end{tabular}

the intention of the brewer. The activity of these enzymes converts the starches of the grains to dextrins and then to fermentable sugars such as maltose. There are several key enzyme groups that take part in the conversion of the grain starch to sugar at certain temperature. When mashing malted grain, the brewer is concerned with two main classes of enzymes: proteases (or proteolytic enzymes) and diastases (or diastatic enzymes). Proteolytic enzymes break down long, complex chains of protein molecules into simpler and more useful proteins and amino acids. Diastatic enzymes convert starch molecules into fermentable sugar and unfermentable dextrins. Each of these enzymes is favored by different temperature and $\mathrm{pH}$ conditions. A brewer can control the variation of mash temperature to favor each successive enzyme's function and thereby customize the wort to the brewer's taste.

In large breweries, the optimal utilization of the brewery equipment is economically necessary, and there is at least one dedicated vessel for mashing. In decoction processes there must be at least two. The vessel has a good stirring mechanism to keep the temperature of the mash uniform, and a heating device that is efficient but will not scorch the malt (often steam), and the vessel should be insulated to maintain rest temperatures. To optimize the mashing procedure, for mashing with $100 \%$ malted barley, a temperature-programmed mashing profile needs to be selected. ${ }^{[9]}$ Several parameters are important during mashing, including temperature, time, and mash thickness.

\section{Enzymatic Rests}

In step infusion and decoction mashing, the mash is heated to different temperatures ${ }^{[10,11]}$ at which specific enzymes work optimally. Table 1 shows the optimal temperature for the enzymes that brewers most pay attention to, and what material those enzymes break down. There is some contention in the brewing industry as to just what the optimal temperature is for these enzymes, as it is often very dependent on the $\mathrm{pH}^{[12]}$ of the mash and its thickness. A thicker mash acts as a buffer for the enzymes. Once a step is passed, the enzymes active in that step are denatured and become permanently inactive. The time between rests is preferably as short as possible, but 
if the temperature is raised more than $1^{\circ} \mathrm{C}$ per minute, ${ }^{[10,11]}$ enzymes may be prematurely denatured in the transition layer near heating elements. At the end of the mashing, the hot wort is cooled to a temperature favorable to the yeast. Once sufficiently cooled, the yeast is added, or pitched, to begin the fermentation process. As this delicate mashing process involves pauses at certain temperatures and takes place in a "mash tub," it necessitates a controlled heating procedure, which can be implemented by a programmable heating instrument.

\section{BLOCK DIAGRAM DESCRIPTION}

The block diagram of the microcontroller-based temperature programmer for the mashing apparatus is as shown in Figure 1.

\section{Mash Tub}

The mashing apparatus consists of a water bath (mash tub) with four cups heated indirectly by heating the water. The water-bath vessel is made of 1.6-mm-thick En 304 grade stainless steel (SS) with a double wall filled with glass insulation to prevent heat loss. The cups used are made up of stainless steel or copper or brass, depending upon the requirement. The water bath vessel is fitted with a $2.5-\mathrm{kW}$ heating coil to heat the water at the desired rate, which is crucial for enzyme studies. There are five stirrers;

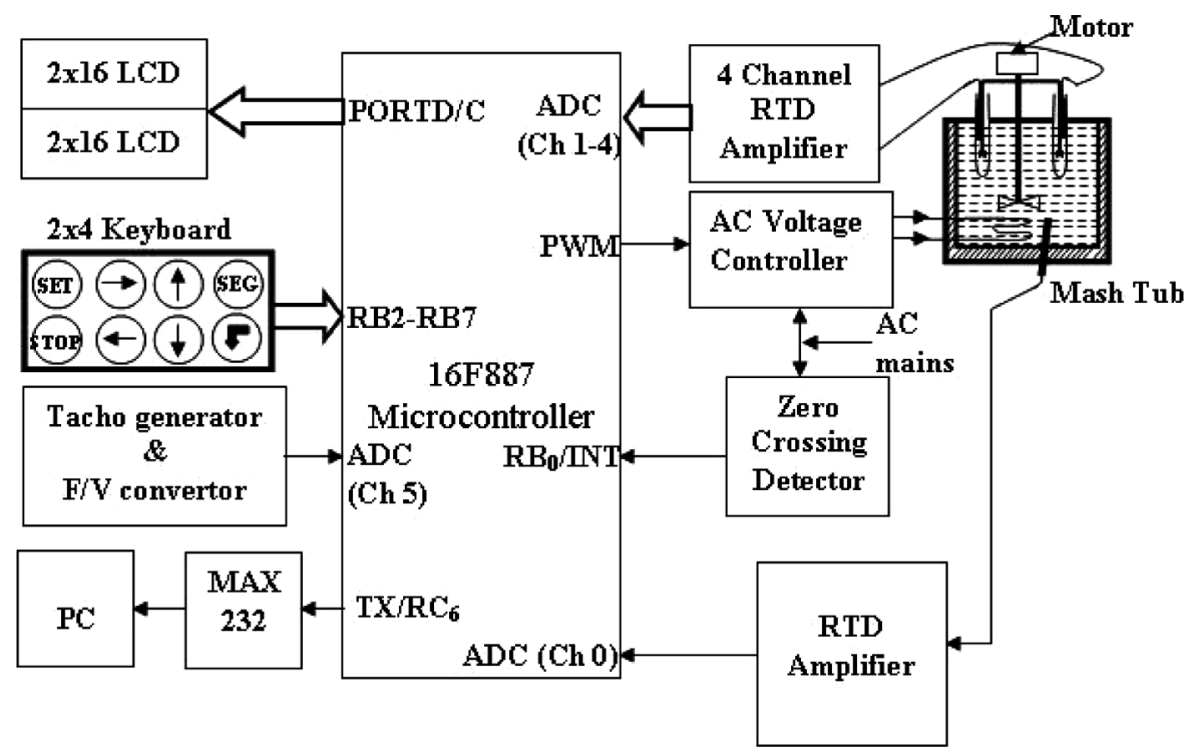

FIGURE 1 Block diagram of the microcontroller-based temperature programmer for mashing apparatus. 
among them, four will be used for sample stirring to keep the temperature of the mash uniform and the remaining one is for stirring the water bath to maintain homogeneity in temperature. The stirrer is driven by a DC motor with a gearbox to stir at 100 or $200 \mathrm{rpm}$.

\section{Temperature Programmer}

The temperature programmer consists of the following main blocks: a programmable AC voltage controller, RTD amplifiers, keyboard, LCD displays, and a microcontroller.

\section{RTD Amplifier}

To control the temperature of the mash tub accurately and to display the temperature of the sample inside the cups, the temperatures of the water bath and sample inside the cups have to be monitored. These temperatures are measured using resistance temperature detectors (RTDs), PT100 (five numbers). RTDs are nearly linear over a wide range of temperatures and response time is quite small. They are among the most precise temperature sensors available with resolution and measurement uncertainties $\pm 0.1^{\circ} \mathrm{C}$. The advantages of RTDs include stable output for long period of time, ease of recalibration, and accurate readings over relatively narrow temperature spans. Their disadvantages compared to the thermocouple sensors are smaller overall temperature range, higher initial cost, and being less rugged in high-vibration environments.

In this application the maximum temperature that can be measured is around $100^{\circ} \mathrm{C}$. The PIC16F887 microcontroller has a 10-bit internal ana$\log$ /digital converter (ADC) with resolution of $4.87 \mathrm{mV}$ for $5 \mathrm{~V}$ reference. The RTD used is type PT100, which is has a resolution of $0.385 \mathrm{mV} /{ }^{\circ} \mathrm{C}$. When it is fed with current of $1 \mathrm{~mA}$, the voltage across PT100 is $100 \mathrm{mV}$ for $0^{\circ} \mathrm{C}$ and $138.5 \mathrm{mV}$ for $100^{\circ} \mathrm{C}$. The output of PT100 is fed to the amplifiers, which must amplify $100 \mathrm{mV}-138.5 \mathrm{mV}$ to $0-4.88 \mathrm{~V}$, corresponding to temperature range of 0 to $100^{\circ} \mathrm{C}$.

The RTD amplifiers are designed using quad operational amplifiers (op-amps) TL084 as shown in Figure 2 (one representative circuit is shown). A compensation circuit for offsetting $100 \mathrm{mV}$ is also used to set the output voltage to a $0 \mathrm{~V}$ at the zero temperature. Outputs of the amplifiers are fed to ADC channels 0 to 4 of the microcontroller.

\section{Programmable AC Voltage Controller}

The programmable AC voltage controller (Figure 2) is designed to control the temperature of the mash tub by controlling root mean 


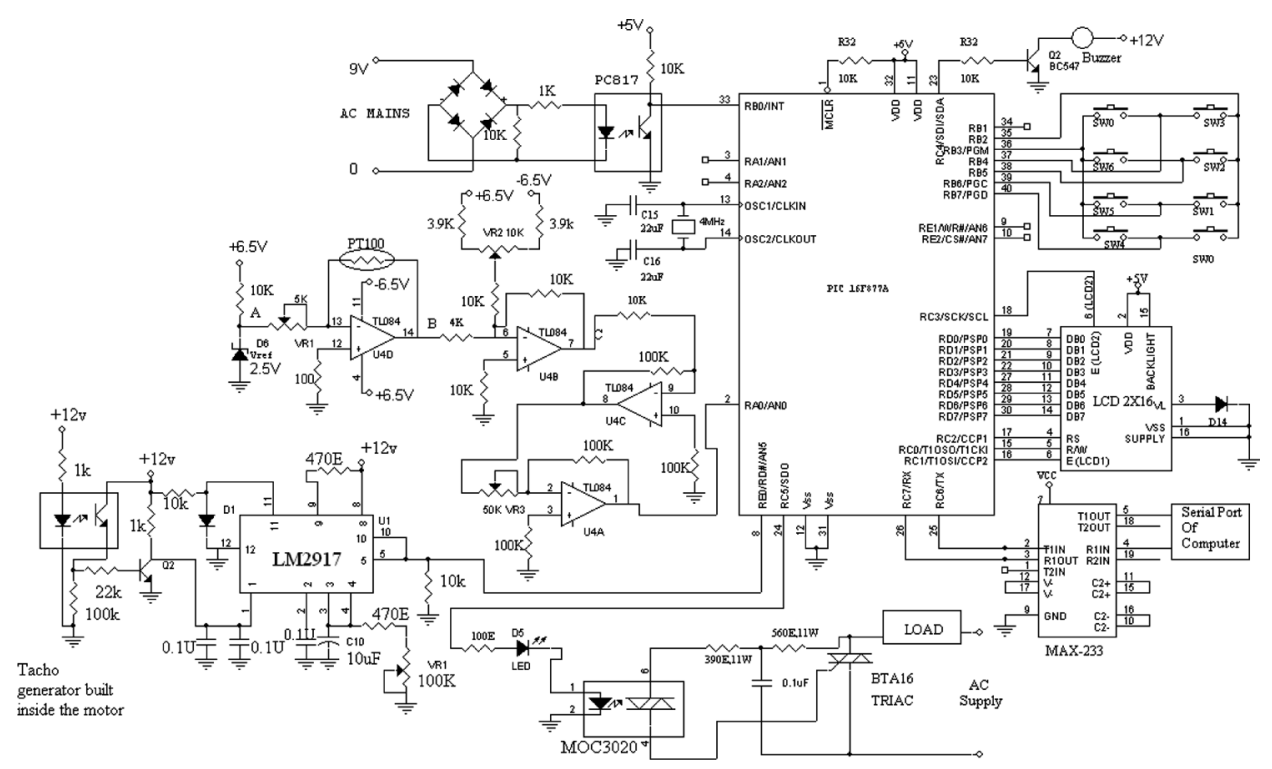

FIGURE 2 The circuit schematic.

square (rms) voltage applied to the mash tub heater (load). The PWM output at $\mathrm{RC}_{5}$ of the microcontroller is used to trigger the TRIAC and in turn vary the voltage applied to the mash tub heater. The PWM pulses used to trigger the TRIAC should be in synchronization with the zero crossing reference of the AC mains. A zero crossing detector is constructed to generate the pulses at each half cycle of the AC mains (Figure 2) to have synchronization. The output of the $0-9 \mathrm{~V}$ step-down transformer is rectified using the bridge rectifier constructed using the IN4007 diodes. The rectified output is pulsating DC, fed to the optocoupler PC817, which provides DC supply isolation. The pulses at the zero crossing of the AC mains are obtained at the collector of the transistor of the optocoupler PC817, which is fed to the external interrupt $\left(\mathrm{RB}_{0} /\right.$ INT) pin of the microcontroller.

The firing pulses are generated at port pin $\mathrm{RC}_{5}$ of microcontroller (16F887) using Timer 1 and the zero crossing detector. When the zero crossing pulse (interrupt) appears at the $\mathrm{RB}_{0} /$ INT pin of the microcontroller, the $\mathrm{RC}_{5}$ pin is made low and timer 1 is loaded with an appropriate value depending on the firing angle calculated by the PID controller; the $\mathrm{RC}_{5}$ pin is made high upon timer 1 overflow interrupt. The PWM output is fed as an input to the optocoupler MOC3020, which provides isolation between the microcontroller circuit and the high power TRIAC circuit.

The AC mains supply is applied across the TRIAC BTA12/600 in series with the load (mash tub heater). The triggering of the TRIAC is done with 
respect to the leading edge of the gate pulse. The position of the leading edge of the pulse is controlled by the microcontroller.

\section{Keyboard Interface}

The $2 \times 4$ matrix keyboard has been interfaced to PORTB of the microcontroller using the interrupt on-change feature of the PORTB. The keyboard is used to enter the end temperature and time of different segment and also to select various functions. The keyboard consists of eight push-button switches, the functional assignments for the switches is as follows (Figure 1): program select (PGM) key for selection of the different programs, enter (ENTER) key to command the microcontroller to execute the selected program, segment selection key (SEG) to select one segment out of nine possible segments to set end temperature or time of the corresponding segment, increment and decrement (INC and DEC) keys to increment or decrement values of selected digit and also to select program number, shift left and shift right keys to shift the cursor left or right on the LCD to set value of each digit of the temperate and time independently, and end key (END) to stop the process during temperature control program execution.

\section{RPM Display}

The DC motor used for stirring has a built-in opto-interrupter, which functions as a tacho-generator. The square waves from the tacho-generator are fed to the frequency-to-voltage $(\mathrm{F} / \mathrm{V})$ converter LM2917 ${ }^{[13]}$ (Figure 2), which is calibrated against a standard tachometer. The output of the $\mathrm{F} / \mathrm{V}$ converter is connected to ADC channel 5 of the microcontroller and the rpm value is displayed on LCD.

\section{Microcontroller}

The microcontroller PIC $16 \mathrm{~F} 887^{[14]}$ used is a 40-pin 8-bit CMOS FLASH High performance RISC microcontroller, which has a 10-bit, 14-channel ADC. The output of the RTD amplifiers corresponding to the mash tub is fed to the ADC channel 0 (Figure 2) and the output of the RTD amplifiers corresponding to the four sample cups are fed to ADC channels 1 to 4 (which are not shown in Figure 2). Two $2 \times 16$ LCD displays are interfaced to display temperature of the mash tub, time, appropriate messages while reading different parameters (LCD1), temperature of four sample cups, and RPM of the motor (LCD2).

Transmit $\left(\mathrm{RC}_{6}\right)$ and receive $\left(\mathrm{RC}_{7}\right)$ pins of the microcontroller are connected to the receive and transmit pins of the serial port of personal computer (PC) via and RS-232 interface. 


\section{SOFTWARE}

The software developed for the system consists of two modules.

\section{Firmware}

In this system it is essential to control the variation of mash temperature to favor each successive enzyme's function and thereby customize the wort to the brewer's taste. The firmware has been developed using $\mathrm{C}$ language to set the end temperature and time of the nine segments of nine temperature profiles through keypad. In this system a facility has been provided to select one profile out of nine temperature profiles to run the temperature control (PID) program.

The microcontroller has been programmed to read the temperature of the mash tub and the temperature of four sample cups through the ADC of the microcontroller. The PID controller has been implemented to control the rate of rise of temperature as per user settings. Simultaneously, the microcontroller transmits the temperature of the mash tub to a PC serially. Also, a program has been written to display the temperature of the mash tub and the time (hr:min:sec) on LCD1 and the temperature of the four samples and rpm of the motor on LCD2.

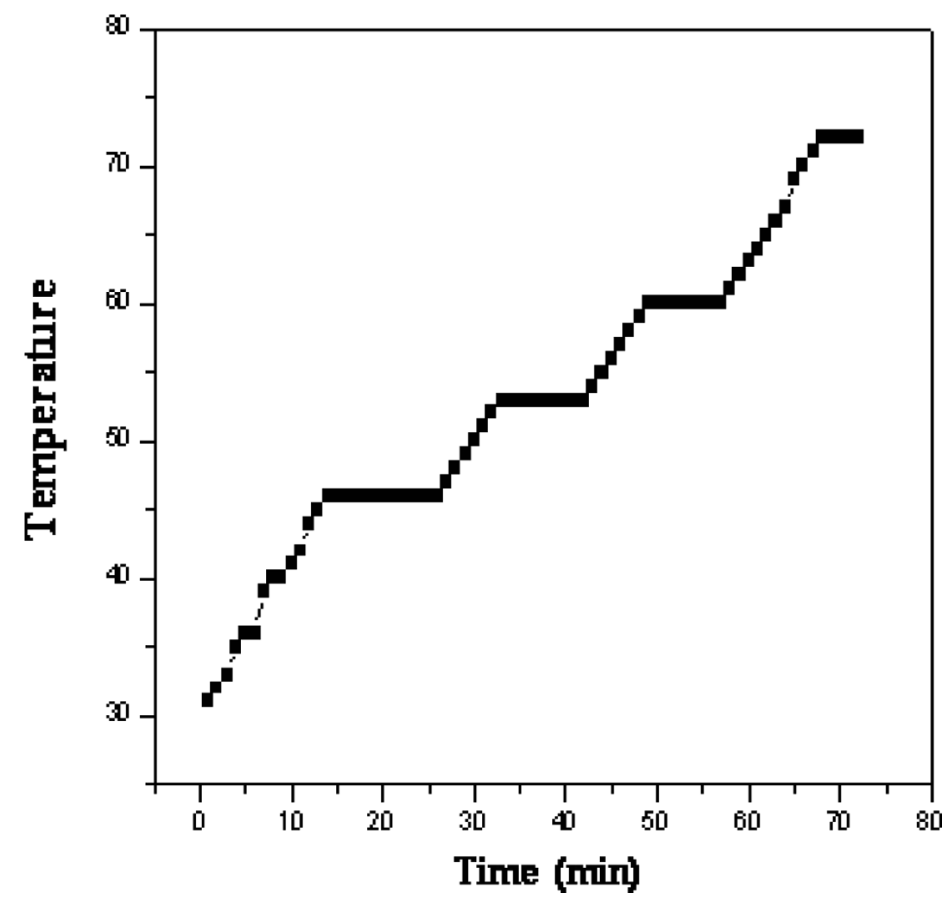

FIGURE 3 Variation of temperature of mashing tub vs. time. 


\section{Software for the PC}

Graphic user interface (GUI)-based software for the PC has been developed using $\mathrm{C}$ to receive the temperature of the mash tub from the microcontroller. The temperature thus received is stored and a graph of the temperature rise with respect to time is plotted, which is useful for tuning the PID.

\section{Tuning of PID Controller}

The PID controller parameters, the gains of the proportional, integral, and derivative terms, if chosen incorrectly, can make the controlled process input unstable - i.e., its output diverges, with or without oscillation, and is limited only by saturation. Tuning a control loop is the adjustment of its control parameters (gain/proportion band, integral gain/reset, and derivative gain/rate) to the optimum values for the desired control response. Tuning of the PID controller has been done by a manual tuning method.

\section{RESULTS}

The temperature of the mash tub received by the PC serially from the microcontroller is stored, and variation of the temperature with respect to

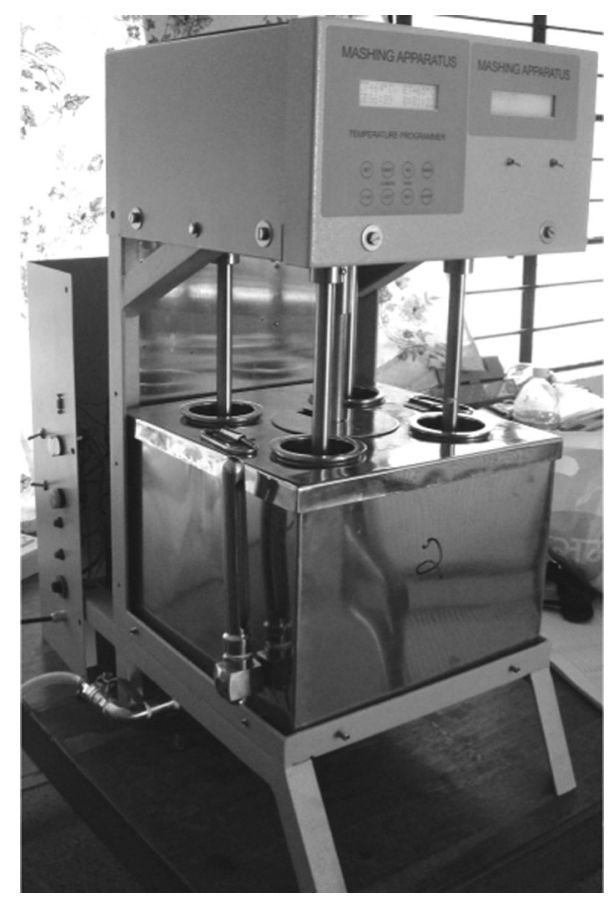

FIGURE 4 Mashing apparatus. 
time is shown in Figure 3. A photograph of the mashing apparatus built is shown in Figure 4.

\section{CONCLUSIONS}

As controlling the temperature is crucial in the mashing process, this instrument not only facilitates heating control, but the order of the heating profile can be programmed or customized. The microcontroller-based nine-profile, nine-segment temperature programmer and four-channel temperature and rpm display system for the mashing apparatus has been designed and implemented using a PIC 16F887 microcontroller. The software for the microcontroller has been developed using $\mathrm{C}$ language to implement the PID controller to control the temperature of the mash tub and can also be used to communicate with the PC to store the temperature data. The instrument has been tested for its operation and is installed. The instrument can find applications in malthouses, breweries, and laboratories.

\section{REFERENCES}

1. European Brewery Convention. Analytica-EBC, 5th ed.; Fach-verlag Hans Carl: Nürnberg, Germany, 1998.

2. Arnold, J. P. Origin and History of Beer and Brewing: From Prehistoric Times to the Beginning of Brewing Science and Technology; BeerBooks: Cleveland, OH, 2005; p. 34. Originally published 1911.

3. Nelson, M. The Barbarian's Beverage: A History of Beer in Ancient Europe, Routledge: London, 2005; p. 6.

4. Goldammer, T. The Brewers Handbook; Apex, 2000; chapter 6. Apex Publishing Ltd.: Essex, UK, 2000.

5. Rabin, R.; Forget, C. The Dictionary of Beer and Brewing; Taylor \& Francis: Philadephia, 1998; p. 180.

6. Ensminger, A. Foods $\mathcal{E}$ Nutrition Encyclopedia; CRC Press: Boca Raton, FL, 1994; Vol. 1, p. 188.

7. Briggs, D. E.; Hough, J. S.; Stevens, R.; Young, T. W. Malting and Brewing Science, 1981; Vol. 1, Malt and Sweet Wort. Kluwer Academic/Plenum Publisher: Suffolk, Great Britain, 1981.

8. Rehberger, A. J.; Luther, G. E. Brewing. In Handbook of Brewing; Hardwick, W. A., Ed.; Marcel Dekker: New York, 1995; pp. 247-322.

9. Wijngaard, H. H.; Arendt, E. K. Optimisation of a Mashing Program for $100 \%$ Malted Buckwheat. J. Inst. Brew. 2006, 112(1), 57-65.

10. Goode, D. L.; Wiltschko, E. A.; Ulmer, H. M.; Arend, E. K. Application of the Rapid Visco Analyser as a Rheologiccal Tool for the Characterisation of Mash Viscosity as Affected by the Level of Barley Adjunct. J. Inst. Brew. 2005, 111(2), 165-175.

11. Goode, D. L.; Wijngaard, H. H.; Arendt, E. K. Mashing With Unmalted Barley-Impact of Malted Barley and Commercial Enzyme (Bacillus spp.) Additions. MBAA TQ 2005, 42(3), 184-198.

12. Kunze, W. Technology Brewing and Malting, Berlin: VLB, 2004; pp. 214-218.

13. National semiconductors Monolithic IC data sheet.

14. Microchip PIC16F887 microcontorller data sheet. 
Copyright of Instrumentation Science \& Technology is the property of Taylor \& Francis Ltd and its content may not be copied or emailed to multiple sites or posted to a listserv without the copyright holder's express written permission. However, users may print, download, or email articles for individual use. 